\title{
A DIMENSÃO ESPACIAL DA REDE DE FLORES E PLANTAS ORNAMENTAIS DO ESTADO DO RIO DE JANEIRO: UMA ANÁLISE A PARTIR DO MUNICÍPIO DE NOVA FRIBURGO, ENTRE OS ANOS DE 2002 E 2018
}

\author{
THE SPACE DIMENSION OF THE ORNAMENTAL PLANTS AND FLOWERS NETWORK OF THE STATE OF RIO DE \\ JANEIRO: AN ANALYSIS FROM NOVA FRIBURGO MUNICIPALITY, BETWEEN 2002 AND 2018
}

\section{RESUMO}

Dados globais sobre o comércio mundial de flores e plantas ornamentais mostram o crescimento da produção e consumo desse segmento nas últimas décadas, inclusive no Brasil. Este artigo mostra como o comércio de flores e plantas ornamentais está organizado em forma de redes geográficas, na medida em que tanto a produção quanto o consumo articulam diferentes espaços. Na constituição da rede de flores e plantas ornamentais, torna-se imprescindível a identificação dos seus agentes ou elementos espaciais e das interações estabelecidas entre eles. Tais interações ocorrem em diferentes escalas (local, regional, nacional ou global). Tanto a conexão quanto a escala - marcas da dimensão espacial - são amplamente influenciadas pela dimensão temporal, que, por sua vez, é influenciada pela intensidade dos fluxos, duração e frequência. Essas considerações são importantes para a identificação das diferentes redes de flores e plantas ornamentais tratadas ao longo da pesquisa: a global, liderada pelas relações estabelecidas pela Holanda; a nacional, a partir da atuação das cooperativas de São Paulo, e a regional, por meio da rede de flores e plantas ornamentais encontrada no território fluminense. Nesse território, a formação da rede de flores e plantas ornamentais é analisada a partir das interações espaciais estabelecidas pelo espaço rural de Nova Friburgo, município que apresenta o maior número de produtores do estado e que se destaca no cultivo de flores de corte. O recorte temporal tem início em 2002 e se estende até o ano de 2018, quando foram realizadas as últimas pesquisas de campo. O caminho metodológico tem como referência a abordagem qualitativa, tanto na seleção dos referenciais teóricos quanto na análise dos dados coletados em campo por meio de observações, imagens, diagnósticos do segmento e entrevistas com os agentes espaciais da rede. Espera-se que esta pesquisa sirva como mais um instrumento de reflexão para a tomada de decisão de ações que possam contribuir para o desenvolvimento de um segmento tão relevante para o estado do Rio de Janeiro.

Palavras-chave: Redes geográficas. Dimensão espacial. Flores e plantas ornamentais. Estado do Rio de Janeiro. Município de Nova Friburgo.

\section{ABSTRACT}

Global data on world trade in flowers and ornamental plants show the growth of production and consumption of this segment in recent decades, including in Brazil. This research shows how the trade in flowers and ornamental plants is organized in the form of geographic networks, since both production and consumption articulate different spaces. In the constitution of the network of flowers and ornamental plants, it is essential to identify its agents or spatial elements and the interactions established between them. The interactions between these agents occur at different scales (local, regional, national or global). Both the connection and the scale - marks of the spatial dimension - are largely influenced by the temporal dimension, which in turn is influenced by the intensity of flows, duration and frequency. These considerations are important for the identification of the different networks of flowers and ornamental plants addressed during the research: the global, led by the relations established by the Netherlands; the national, based on the activities of the cooperatives of São Paulo, and the regional, through the network of flowers and ornamental plants found in the territory of Rio de Janeiro state. In the territory of the state of Rio de Janeiro, the formation of the network of flowers and ornamental plants is analyzed from the spatial interactions established through the rural area of Nova Friburgo, the municipality with the largest number of producers in the state and which stands out in the cultivation of
D Jorge Luiz Costa da Silva Reis ${ }^{a}$

Dlaucio José Marafon ${ }^{a}$

${ }^{a}$ Universidade do Estado do Rio de Janeiro (UERJ), Rio de Janeiro, RJ, Brasil

DOI: $10.12957 /$ geouerj.2020.47278

Correpondência: glauciomarafon@hotmail.com

Recebido em: 20 set. 2019 Revisado em: 19 out. 2019 Aceito em: 13 dez.2019 
cut flowers. The time cut begins in 2002, and extends until the year 2018, when the last field surveys were carried out. The methodological path has as its reference the qualitative approach such in the selection of the theoretical references as in the analyses of the field collected data though observation, images, segment diagnostics and interviews with network space agents. It is hoped that this research will serve as a further reflection tool for the decision-making of actions that may contribute to the development of such a relevant segment to the state of Rio de Janeiro.

Keywords: Geographic networks. Spatial dimension. Flowers and ornamental plants. Rio de Janeiro state. Municipality of Nova Friburgo. 


\section{INTRODUÇÃO}

O aumento da produção e do comércio de flores e plantas ornamentais, nas mais variadas escalas, permite o estudo da floricultura por meio das redes geográficas, na medida em que tanto a produção quanto o comércio articulam diferentes espaços. Para o entendimento dessa temática, foi de extrema importância observações feitas pelo professor Roberto Lobato Corrêa (2011) acerca das redes geográficas. Na constituição da rede de flores e plantas ornamentais, torna-se imprescindível a identificação dos seus agentes ou elementos espaciais, conforme apontam Santos (1992) e Corrêa (2011). São considerados como tais os produtores, as empresas fornecedoras de insumos, os equipamentos e mudas, o Estado e as suas instituições, assim como os próprios consumidores dessa cadeia produtiva na dimensão organizacional. As interações entre esses agentes se dão em diferentes escalas espaciais (local, regional, nacional ou global). Tanto a conexão quanto a escala - marcas da dimensão espacial - são amplamente influenciadas pela dimensão temporal, que, por sua vez, é influenciada pela intensidade dos fluxos, duração e frequência. Essas considerações, baseadas em Corrêa (2011), são importantes para a identificação das diferentes redes de flores e plantas ornamentais tratadas neste trabalho: a global, liderada pelas relações estabelecidas pela cooperativa holandesa FloraHolland; a nacional, a partir da atuação das cooperativas de São Paulo, e a regional, mediante a rede de flores e plantas ornamentais encontrada no território fluminense. No caso específico da rede de flores do estado do Rio de Janeiro, este artigo busca o seu entendimento a partir das relações estabelecidas pelo espaço rural do município de Nova Friburgo - maior produtor de flores de corte de todo o estado do Rio de Janeiro (SEAPEC/ EMATER-Rio, 2015).

De acordo com informações coletadas de forma preliminar em 2016, a floricultura fluminense apresentou crescimento expressivo nos últimos anos. Essas informações, divulgadas tanto por fontes institucionais do governo ${ }^{1}$, quanto pela mídia privada, como o Jornal O $\mathrm{Dia}^{2}$, davam conta de que o estado do Rio de Janeiro já havia se consolidado como o segundo maior produtor de flores e plantas ornamentais do Brasil, perdendo o posto de maior produtor apenas para o estado de São Paulo. Dados disponibilizados pelo governo estadual em seu site indicam que a Região Serrana aparece como a principal produtora de flores e plantas ornamentais do estado do Rio de Janeiro, com destaque para o município de Nova Friburgo.

Interessa saber quais elementos espaciais participam da rede de flores e plantas ornamentais no estado do Rio de Janeiro, particularmente por meio das práticas espaciais observadas a partir do espaço rural do município de Nova Friburgo. Por se tratar de um estudo que tem como recorte um espaço rural, cabem reflexões em relação aos impactos provocados nesse espaço pela modernização que se encontra em curso, seja pela expansão das atividades não agrícolas, como o turismo rural, ou pelo uso cada vez maior de

\footnotetext{
1 Disponível em: http://www.rj.gov.br/web/seapec. Acesso em: 16 ago. 2016.

2 Disponível em: http://odia.ig.com.br/odiaestado/2014-06-29/flores-se-expandem-no-interior.html. Acesso em: 16 ago. 2016.
} 
tecnologia no processo produtivo da agropecuária, como, por exemplo, a utilização de máquinas, sementes, mudas modificadas geneticamente, insumos ou mesmo pelos investimentos nos espaços de circulação que possam intensificar os fluxos da produção. Essas últimas constatações são perceptíveis cada vez mais na rede de produção, comercialização e consumo de flores e plantas ornamentais.

A importância econômica da floricultura pode ser mensurada pelo volume de exportações dos principais agentes da cadeia global desse segmento: em 2013, as cifras ultrapassaram US\$ 21 bilhões ante US\$ 8,77 bilhões em 1999 (NEVES; PINTO, 2015). A Holanda, por meio de sua principal cooperativa, a FloraHolland, é considerado o principal produtor em âmbito mundial, seguido de China, Estados Unidos e Japão. Entretanto, os fluxos comerciais desses últimos países se dão, majoritariamente, dentro de seus espaços, o que tende a limitar a comercialização à escala nacional, diferentemente do que acontece com a Holanda, que apresenta uma dimensão espacial marcada pelas suas relações globais. Apesar do papel hegemônico da Holanda, novos polos vêm apresentando aumento na participação desse segmento na dimensão global, entre eles: Colômbia, Quênia, Equador e Etiópia.

O Brasil, embora não seja considerado um grande exportar de flores e plantas ornamentais, vem apresentando crescimento com esse agronegócio nas últimas décadas. Segundo informações expostas no estudo "Caracterização do setor produtivo de flores e plantas ornamentais no Brasil", realizado pelo Instituto Brasileiro de Geografia (IBGE), as mudanças evidenciadas estão inseridas na expansão do capitalismo internacional. O estudo em destaque foi muito importante para uma análise de tal produção no país. Ao fazer um diagnóstico do segmento, esse instituto contribuiu para o seu conhecimento em âmbito nacional, além de apontar o seu potencial socioeconômico. Cabe ressaltar que o desenvolvimento do segmento de flores e plantas ornamentais teve grande contribuição dos imigrantes, principalmente holandeses e japoneses. Graças à atuação desses agentes espaciais, especialmente a dos holandeses, por meio do cooperativismo em São Paulo, ocorreu a expansão dessa produção no Brasil que, aos poucos, foi se organizando em rede em âmbito nacional, tendo justamente o estado de São Paulo como o principal articulador da rede, que, atualmente, apresenta uma dimensão espacial nacional. Desse modo, percebe-se a presença de flores e plantas ornamentais de São Paulo - notadamente, do município de Holambra -, nos principais mercados varejistas e atacadistas do país.

No estado do Rio de Janeiro, dados divulgados pelo Instituto Brasileiro de Floricultura (IBRAFLOR), por meio de Neves e Pinto (2015), colocam em evidência o aumento da participação do estado no cenário nacional, tendo contribuído com R\$ 662 milhões do faturamento nacional, em 2014, o equivalente a $12 \%$ da participação brasileira, posicionando-o à retaguarda do estado de São Paulo nesse quesito. Quando comparado com o ano anterior, observa-se um incremento de 15\%. No território fluminense, duas regiões sobressaem-se na produção de flores e plantas ornamentais: as regiões Serrana e Metropolitana, que, entre 
os principais canais de comercialização, apresentam forte concentração no Centro de Abastecimento da Guanabara (CADEG), marcando, desse modo, a dimensão da rede de flores e plantas ornamentais do estado do Rio de Janeiro por meio da dimensão regional.

De qualquer forma, é interessante observar que houve o desenvolvimento da floricultura no estado do Rio de Janeiro, o que vem caracterizando a modernização do seu espaço rural. Essa realidade despertou a atenção do governo estadual, que tentou incrementá-la por um programa específico para o fomento e custeio do setor, intitulado "Florescer" e, desse modo, reforçar as transformações pelas quais tem passado o espaço rural fluminense.

O recorte temporal para o desenvolvimento desse trabalho foi estabelecido a partir do primeiro diagnóstico encontrado sobre esse setor em território fluminense, que data de 2002, feito por Carvalho e Chianca. Logo, foram analisadas as transformações espaciais no período de 2002 até o ano de 2018, marco temporal das últimas pesquisas de campo em Nova Friburgo para a conclusão da dissertação de mestrado ${ }^{3}$. Este artigo, que deriva da dissertação supracitada, tem como objetivo geral analisar a dimensão espacial da rede de flores e plantas ornamentais a partir do espaço rural do município de Nova Friburgo-RJ. Para tanto, são ponderadas as interações espaciais existentes entre os agentes presentes no espaço rural desse município e os demais agentes encontrados em tal rede do estado do Rio de Janeiro. Nesse contexto, foi possível identificar os agentes espaciais presentes nas relações da rede de flores e plantas ornamentais do Rio de Janeiro e, especificamente, em Nova Friburgo (produtores, fornecedores de insumos, equipamentos, representantes das associações e dos mercados atacadistas, técnicos agrícolas e os consumidores), assim como reconhecer a origem dos insumos e equipamentos utilizados das lavouras.

Para o entendimento mais claro das dimensões espaciais citadas, serão analisadas a seguir a rede de flores, respectivamente, nas dimensões global, nacional e regional.

Dimensão global da rede de flores e plantas ornamentais e os seus principais agentes

A Holanda destaca-se no mercado mundial como maior produtor e comercializador de flores e plantas ornamentais, seguido por China, Estados Unidos e Japão. Esses últimos, embora se destaquem como grandes produtores, apresentam alta demanda interna, algo que tende a limitar os fluxos comerciais da rede à escala nacional. Entretanto, chama atenção, nesse mapeamento, outro estudo, sob a responsabilidade da instituição bancária Rabobank, que, apesar de reafirmar o papel hegemônico da Holanda no mercado em evidência,

\footnotetext{
3 REIS, Jorge Luiz Costa da Silva. A dimensão espacial da rede de flores e plantas ornamentais do estado do Rio de Janeiro: uma análise a partir do município de Nova Friburgo, entre os anos de 2002 e 2018. Dissertação (mestrado em Geografia) - Instituto de Geografia, Universidade do Estado do Rio de Janeiro. Rio de Janeiro. 2019. 121 p.
} 
aponta a expansão de novos polos, contribuindo, desse modo, para a dinamização do mercado global. Entre os novos polos, são citados os seguintes países: Colômbia, Quênia, Equador e Etiópia. Assim, esses países, além da Holanda, constituem os principais fornecedores das grandes cadeias varejistas localizadas nas nações centrais, como Estados Unidos e Reino Unido. Porém, convém destacar o papel fundamental desempenhado pelo desenvolvimento tecnológico da cadeia logística internacional, uma das características do atual período técnico-científico-informacional, tão bem explicitado por Santos e Silveira (2002). No que tange especificamente à logística internacional, percebe-se, nas palavras de Neves e Pinto, que:

[...] o contínuo aprimoramento tecnológico da cadeia logística internacional, focando o transporte de itens com alta perecibilidade, tem minimizado o efeito da localização do centro produtor em relação ao centro consumidor" (NEVES e PINTO, 2015, p. 34-35).

Embora a comercialização de flores e plantas ornamentais seja constatada ao longo de todo o ano, notase que há um consumo maior em datas comemorativas, principalmente no dia das mães, namorados e finados. O conhecimento desses eventos torna-se imprescindível para o planejamento dos produtores que, em muitos casos, de forma seletiva, acabam produzindo de acordo com a demanda do mercado. Esta situação evidencia que os fluxos estabelecidos entre os agentes espaciais da rede de flores e plantas ornamentais não se restringem às condições naturais e, desse modo, devem ser compreendidos, também, a partir do calendário de eventos, que, assim, acaba marcando a dimensão temporal da produção de flores e plantas, pois, dependendo da época do ano, a frequência dos fluxos será mais intensa ou menos intensa.

Elias (2002) diz que a tecnologia e o capital subordinam, em parte, a própria natureza, reproduzindo de forma artificial algumas das condições necessárias à produção agropecuária, que, aliás, torna-se cada vez mais dependente dos insumos produzidos pela indústria. Segundo a autora:

[...] Inúmeras pesquisas tecnológicas voltadas para o setor desenvolveram uma gama muito grande de novos produtos químicos na tentativa de: suprir as deficiências do solo; prevenir as doenças das plantas; combater as pragas das plantações; aumentar o rendimento por hectare; fabricar no laboratório sementes mais produtivas; construir máquinas para semear, cultivar, colher, irrigar o solo e uma quantidade incomensurável de outras inovações, proporcionando importantes ganhos de produtividade (ELIAS, 2002, p. 24).

A situação descrita anteriormente pode ser perfeitamente perceptível na figura 1. 
Figura 1. Sistema elétrico utilizado nas estufas para impulsionar o crescimento das flores nos meses maisfrios, na localidade de Stucky - Nova Friburgo - RJ Fonte: REIS, 2018.

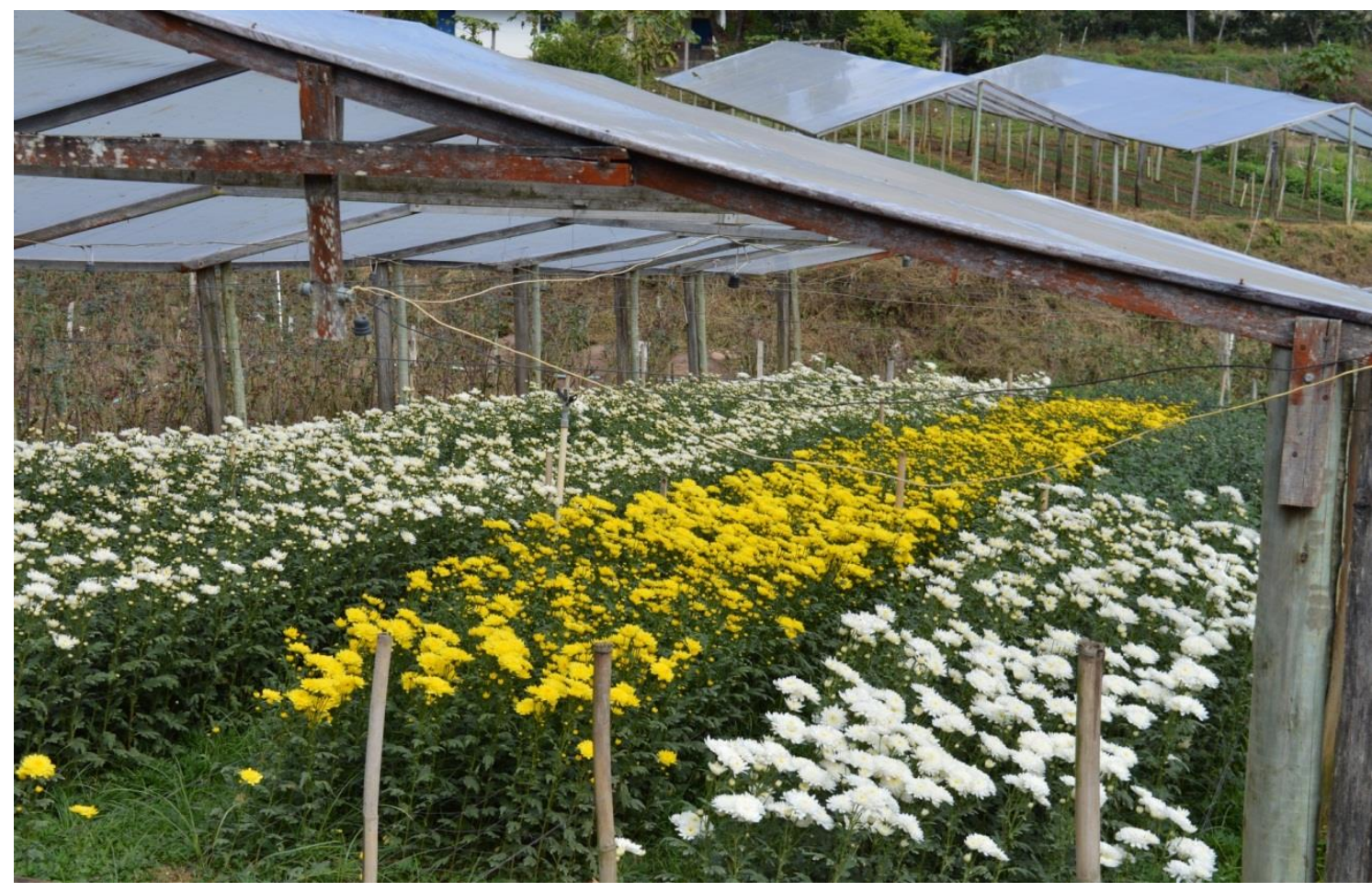

O que se nota é que o desenvolvimento da agropecuária, na atualidade, envolve cada vez mais ciência, tecnologia e informação, a fim de tornar cada vez maior e melhor a produção final, resultando em transformações econômicas e socioespaciais.

A produção brasileira de flores e plantas ornamentais e a sua dinâmica espacial nacional

No que diz respeito ao fortalecimento da produção de flores e plantas ornamentais no Brasil, nota-se que essa situação começa a ganhar contornos a partir de meados dos anos 1950, com forte participação dos imigrantes holandeses e japoneses (TSUBOI; TSURUSHIMA, 2009 apud NEVES e PINTO, 2015). Quando somados, os centros distribuidores de Holambra, São Paulo (CEAGESP) e Campinas (CEASA), representam os maiores centros de comercialização de flores e plantas ornamentais do país, algo que enfatiza o protagonismo do estado paulista na rede nacional desse segmento (REIS, 2019).

Segundo estudos do mapeamento da cadeia de flores e plantas ornamentais do Brasil divulgados em 2015 , do total do volume financeiro comercializado pelos produtores, $97 \%$ foram realizados no mercado interno (NEVES e PINTO, 2015). Tal constatação deixa claro que o mercado consumidor desse seguimento, no Brasil, possui uma dimensão espacial caracterizada pela escala nacional. Ainda que quase toda a produção seja comercializada por meio da rede de flores e plantas ornamentais no mercado interno, não se pode ignorar o 
que o país importa para atender parte de sua demanda que não é atendida totalmente no Brasil. Essa realidade permite entender que, embora essa rede brasileira seja caracterizada majoritariamente pela sua configuração em escala nacional, ela também possui vínculos com outras regiões do planeta e, desse modo, apresenta conexões externas (globais) em sua dimensão espacial, independente da intensidade dos fluxos estabelecidos.

No que diz respeito às mudas de plantas ornamentais, bulbos e rizomas, as importações são realizadas, principalmente, da Holanda, onde são buscadas novas variedades desenvolvidas por empresas especializadas em pesquisas genéticas que possam atender a demanda interna. Na pauta das importações, também chamam atenção as flores que são compradas de outros países, como as rosas obtidas da Colômbia e do Equador.

No ano de 2014, o estado de São Paulo contabilizou o maior número de produtores em todo o território nacional - cerca de 2.288 -, seguido pelos estados do Rio Grande do Sul e do Rio de Janeiro com, respectivamente, 1.550 e 1.030 floricultores (NEVES e PINTO, 2015). O tamanho médio das propriedades produtoras de flores e plantas ornamentais e os valores totais alcançados por essas propriedades nos últimos anos são indicadores que sinalizam, de um modo geral, que as propriedades estão inseridas no processo de modernização do campo que se encontra em curso, uma das marcas do avanço do sistema capitalista, intensiva e extensivamente.

Em suma, pode-se dizer que o modelo da floricultura moderna que se destacou no Brasil a partir das práticas espaciais iniciadas em São Paulo apoiou-se nas relações estabelecidas por intermédio de três agentes: produtores familiares especializados; instituições de pesquisa, que, mediante as relações mantidas com os agricultores, permitiram grande dinamismo tecnológico por meio da oferta de novas técnicas de irrigação e produção de novas variedades; e organização dos produtores em cooperativas, na configuração dos mercados, algo que foi fundamental na propagação de tecnologias e prestação de assistência técnica. A atuação desses três agentes espaciais em território paulista corrobora com a prática classificada por Corrêa (2002) como seletividade espacial, isto porque as características encontradas nesse espaço foram fundamentais para o seu desenvolvimento.

Ainda que o setor de flores e plantas ornamentais esteja concentrado no estado de São Paulo, sob forte influência das cooperativas, que praticamente formam e comandam a rede desse segmento em âmbito nacional e que tiveram papel preponderante nas transformações e modernização das regiões pioneiras, não se pode negar a importância de outros estados no cenário brasileiro, como Minas Gerais, Santa Catarina, Rio Grande do Sul, Brasília, Ceará e, especificamente, o Rio de Janeiro, onde se pretende analisar a formação da rede de flores e plantas ornamentais por meio das interações espaciais estabelecidas. Por isso, faz-se necessário traçar um diagnóstico da produção de flores e plantas ornamentais do território fluminense. 
A produção e comercialização de flores e plantas ornamentais do estado do Rio de Janeiro e a sua dinâmica regional

Há uma concentração desses cultivos nas regiões Serrana e Metropolitana. Essas regiões concentram $88 \%$ da produção estadual de flores e plantas ornamentais (SEAPEC/ EMATER-Rio, 2015). Enquanto na região Metropolitana, os municípios do Rio de Janeiro e Itaboraí apresentam-se como os principais produtores, com ênfase na produção de plantas ornamentais, flores e folhagens tropicais; Nova Friburgo, Bom Jardim e Petrópolis apresentam-se como os principais municípios da região Serrana, com destaque para o cultivo de flores de corte de clima temperado. Na região das Baixadas Litorâneas, dois municípios destacam-se no cultivo de gramas: Silva Jardim e Cachoeiras de Macacu.

As pequenas empresas e os pequenos produtores constituem maioria na floricultura fluminense, ainda que a estrutura produtiva em que estejam inseridos seja bastante diferente na região Serrana e na região Metropolitana, especialmente no município do Rio de Janeiro. Na região Serrana, as empresas são menores e majoritariamente familiares, sendo observadas relações de parceria e baixo nível de contratação de trabalhadores assalariados. Nessas propriedades, os floricultores vivem quase que exclusivamente da floricultura, não sendo observados, nesses espaços, a expansão de atividades não agrícolas (CARVALHO E CHIANCA, 2002).

Na região Metropolitana, a floricultura - caracterizada pelo setor de plantas ornamentais - é formada, especialmente, por empresários de pequeno porte. Contudo, nessa região, a presença de médias e grandes empresas é mais expressiva quando comparada à região Serrana, e o trabalho assalariado é mais marcante que o trabalho familiar. Encontram-se produtores mais profissionalizados, ainda que, de maneira geral, o perfil do produtor fluminense seja classificado como de baixa tecnologia. Há de se frisar, também, que muitos produtores de plantas ornamentais encontram-se na informalidade. Muitos deles vendem para intermediários ou são subcontratados pelos produtores formais. Além dessas características, o setor de plantas ornamentais apresenta muitos produtores que dedicam-se a outras atividades além da produção de plantas.

A comercialização e as dimensões temporal e espacial da rede de flores e plantas ornamentais de Nova Friburgo

Em relação à comercialização, dados obtidos por meio da SEAPEC/EMATER-Rio e entrevistas de campo - realizadas no ano de 2018, em Nova Friburgo - indicam que os produtores comercializam suas mercadorias no mercado do CADEG, considerado o principal mercado atacadista/varejista no segmento de flores e plantas ornamentais do Estado, sendo responsável por, aproximadamente, $70 \%$ a $80 \%$ das vendas. Essas informações podem ser visualizadas no Figura 2. 
Figura 2. Produção e comercialização da floricultura de Nova Friburgo Fonte: Adaptado por Reis, 2019, a partir de entrevistas realizadas em campo com a coordenadora de floricultura do RJ, floricultores, técnicos agrícolas, lojas agrícolas locais e representante do CADEG.

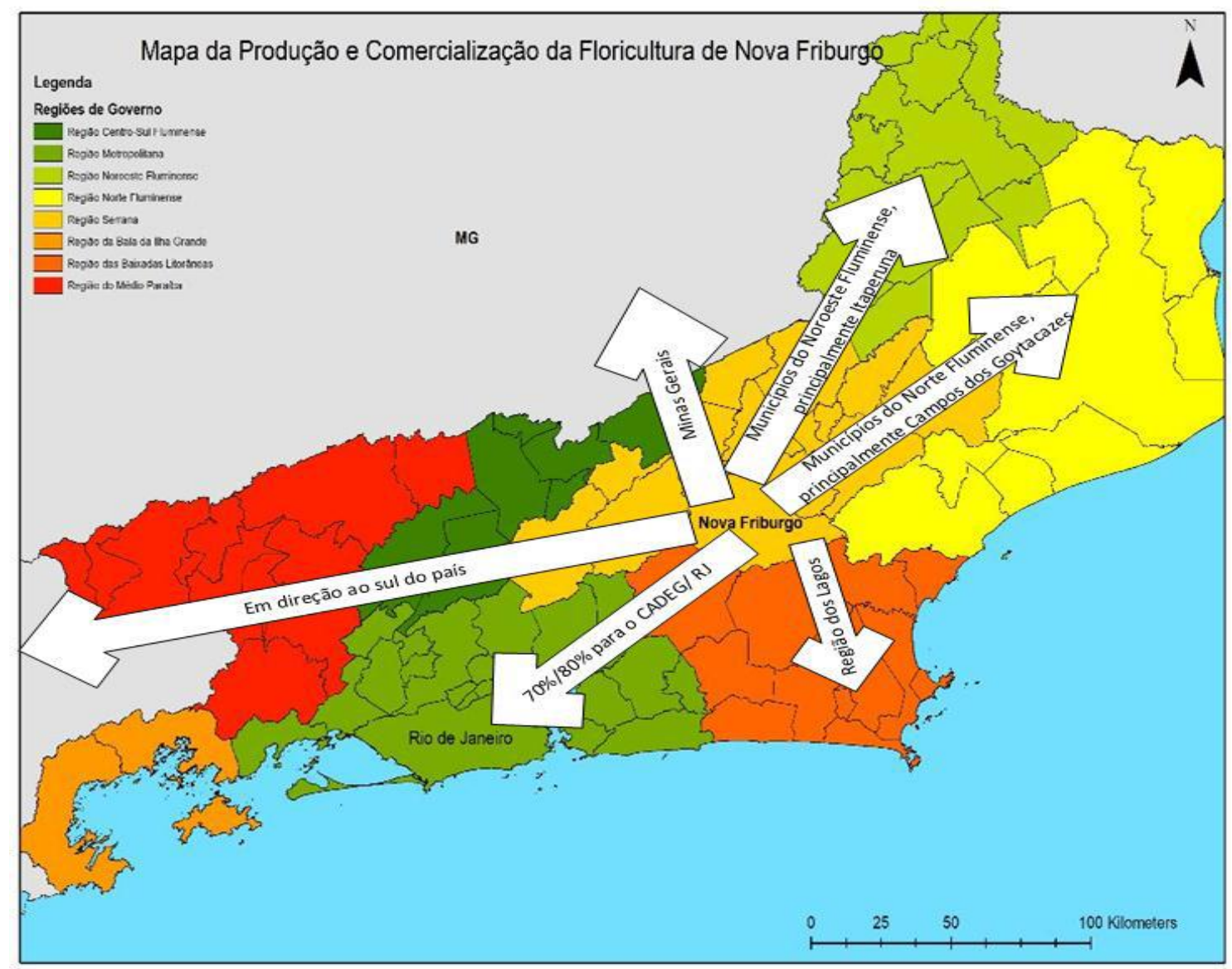

Para o CADEG, convergem, durante a madrugada, um número expressivo de decoradores de casamentos, aniversários, igrejas, lojistas e funerárias. Todavia, durante a manhã, nota-se outro tipo de clientela. Há, portanto, uma diferenciação de público, dependendo horário do dia. Esse fato remete à dimensão temporal, tão bem explicitada por Corrêa (2011), na medida em que os fluxos dentro do próprio mercado são influenciados pela ofertada dos floristas e pela procura dos principais consumidores. Pode-se dizer que os fluxos mais intensos ocorrem entre cinco e seis horas da madrugada, quando os grandes compradores (decoradores, lojistas, funerárias etc.) dirigem-se ao mercado. Depois desse horário, mudam não só a intensidade dos fluxos, como também o público, agora constituído basicamente por consumidores domésticos, que frequentam não só os pavilhões onde são vendidas as flores de corte (figura 3), como, também, os boxes permanentes do CADEG, que funcionam durante todo o dia. 
Figura 3: Pavilhão do CADEG onde são comercializadas as flores e plantas produzidas em território fluminense Fonte: REIS, 2018.

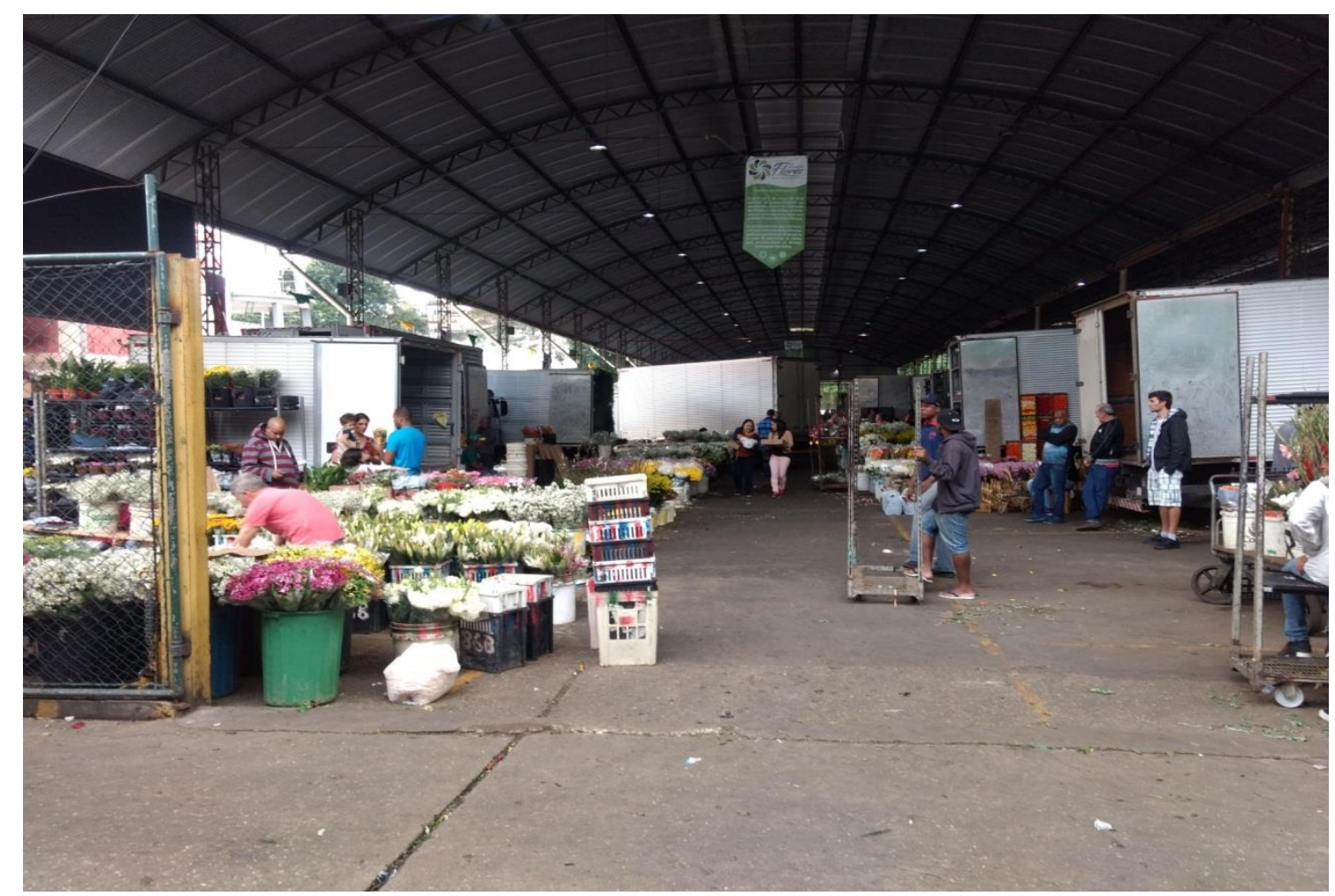

Quase a totalidade do que é produzido em Nova Friburgo é consumido no próprio estado, configurando a escala de consumo numa dimensão regional. Essa realidade destoa do que consta no mapa de origem dos produtos que são consumidos nas lavouras de flores. Neste mapa (que será apresentado a seguir), notam-se produtos de origens de outros estados, o que permitiu o entendimento de que, quando levados em consideração os fornecedores da rede de flores de Nova Friburgo, a dimensão se configura numa escala nacional, pois as fábricas estão instaladas fora do estado do Rio de Janeiro. Essa situação evidencia o quanto a rede de flores e plantas ornamentais do estado do Rio de Janeiro é dependente dos insumos e mudas de outros estados, mormente o de São Paulo, que têm as cooperativas como articuladoras entre produtores e mercado consumidor. No estado do Rio de Janeiro, percebe-se que a articulação é buscada pelo Estado, por meio de projeto setorial.

Apesar das tentativas de intermediação por parte do governo estadual, há um imbróglio envolvendo produtores e a administração do CADEG. Segundo os produtores, os preços cobrados pelo CADEG para o uso do espaço são altos. Todavia, nas palavras do representante do CADEG, o cerne do conflito é o questionamento (por parte da associação dos floricultores) da propriedade do espaço utilizado pelos floricultores, que, segundo esse representante, tem servido de subterfúgio para o não pagamento das mensalidades por parte dos 
produtores, que teriam deixado de pagá-las (a maioria) por não reconhecerem a legitimidade do CADEG sobre um terreno considerado público pela associação que representa os produtores. Nas palavras do diretor social do mercado municipal, os floricultores imprimiram as informações disponibilizadas pelo Google e passaram a questionar na justiça a legitimidade das mensalidades cobradas pelo local.

Além do ponto de comercialização no CADEG, outras formas de venda da produção foram evidenciadas pela SEAPEC/EMATER-Rio, tais como: comercialização em pontos de vendas unitários (hortos/floriculturas/feiras), e nos ramos funerário e de decoração. Alguns produtores também montam barracas para a venda de flores ao longo das vias (figura 4).

Figura 4. Venda de flores em barracas em Nova Friburgo - RJ Fonte: REIS, 2018.

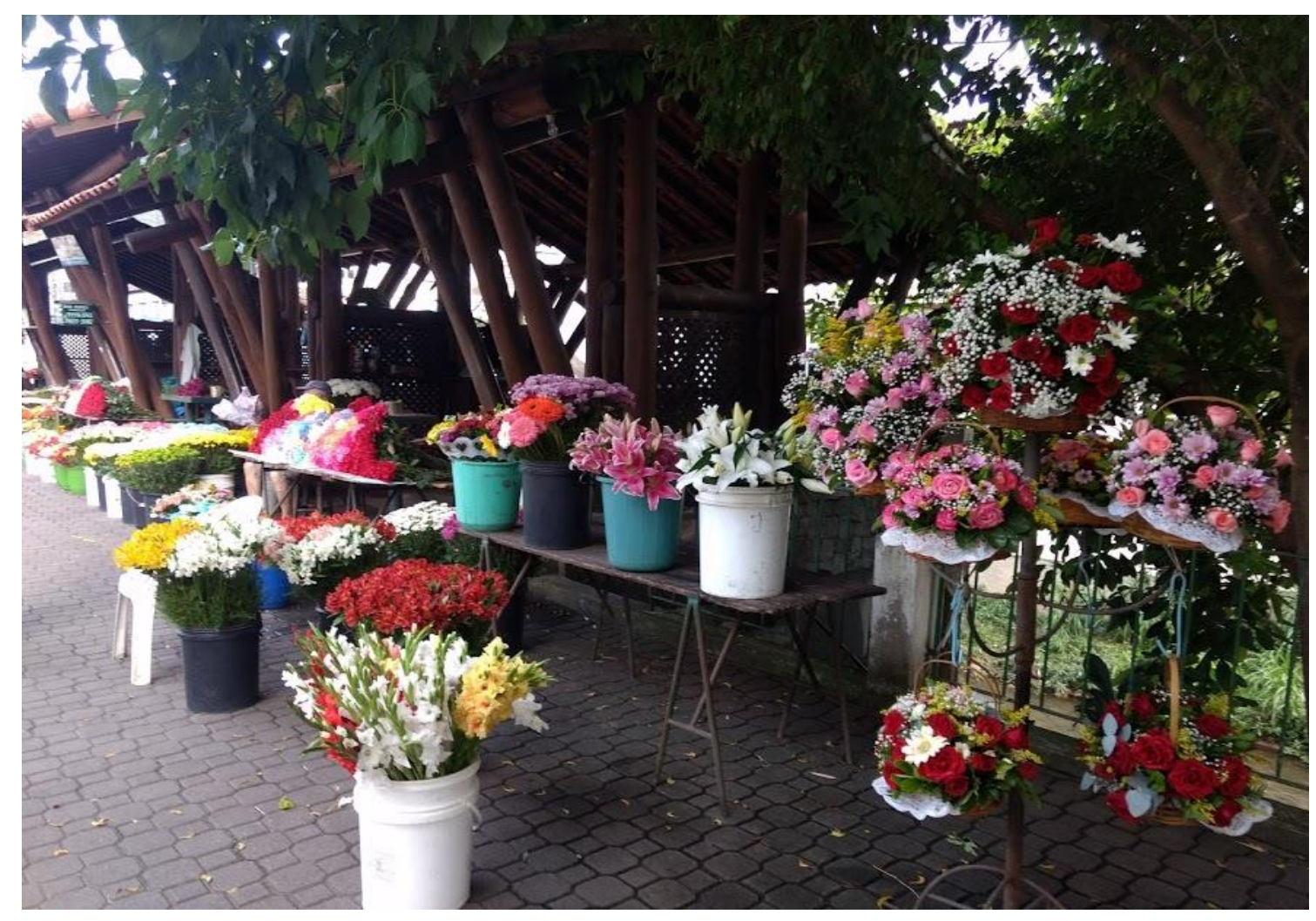

Entraves encontrados na rede de flores e plantas ornamentais do Rio de Janeiro

Entre as debilidades que ainda persistem, destacam-se as seguintes: os setores produtivos - tanto o de flores de corte quanto o de plantas ornamentais - não internalizam totalmente suas cadeias produtivas, o que os tornam dependentes dos insumos oriundos de outros estados, principalmente de São Paulo; utilizam, ainda - e de forma parcial -, padrão tecnológico da Revolução Verde e apresentam custos mais elevados de produção; têm poucas relações com institutos de pesquisa, o que acaba se refletindo na baixa diversificação e qualidade de sua produção quando comparadas ao mercado paulista. 
Além das dificuldades relatadas, somam-se outras, citadas pela SEAPEC/EMATER-Rio (2015) como gargalos que dificultam o desenvolvimento do segmento em território fluminense. Entre as dificuldades: acesso do consumidor aos produtos; carência na prestação de serviços ao floricultor, principalmente quanto à assistência técnica; baixo acesso oficial do produtor às novas espécies; legislação (fitossanitária/comercial/tributária/produtiva) ultrapassada, ineficiente e onerosa, de interpretação dúbia e com alto grau de risco; poucas ações de marketing com continuidade; falta de mão de obra especializada; alto índice de informalidade; carência de informações do setor; falta de padronização para alguns produtos, principalmente na área de paisagismo; baixo uso de técnicas de pós-colheita; falta de capacitação técnica/ administrativa/ informática dos integrantes da cadeia; transporte e acondicionamento ainda deficitários.

As debilidades citadas são consideradas entraves ao desenvolvimento da rede de flores e plantas ornamentais do estado do Rio de Janeiro. Além dessas, foram constatadas em trabalho de campo, no dia 23 de janeiro de 2018, em Vargem Alta e Stucky - duas das principais localidades produtoras de Nova Friburgo , características que tendem a limitar a circulação de pessoas e mercadorias dentro da rede geográfica estabelecida por esse segmento. Quase todas as propriedades encontram dificuldades para escoar a produção, pois as estradas que dão acesso a muitas delas não são asfaltadas, o que acaba influenciando na intensidade dos fluxos. Essa situação é perceptível na figura 5

Figura 5. Estrada na localidade de Vargem Alta, Nova Friburgo - RJ Fonte: REIS, 2018.

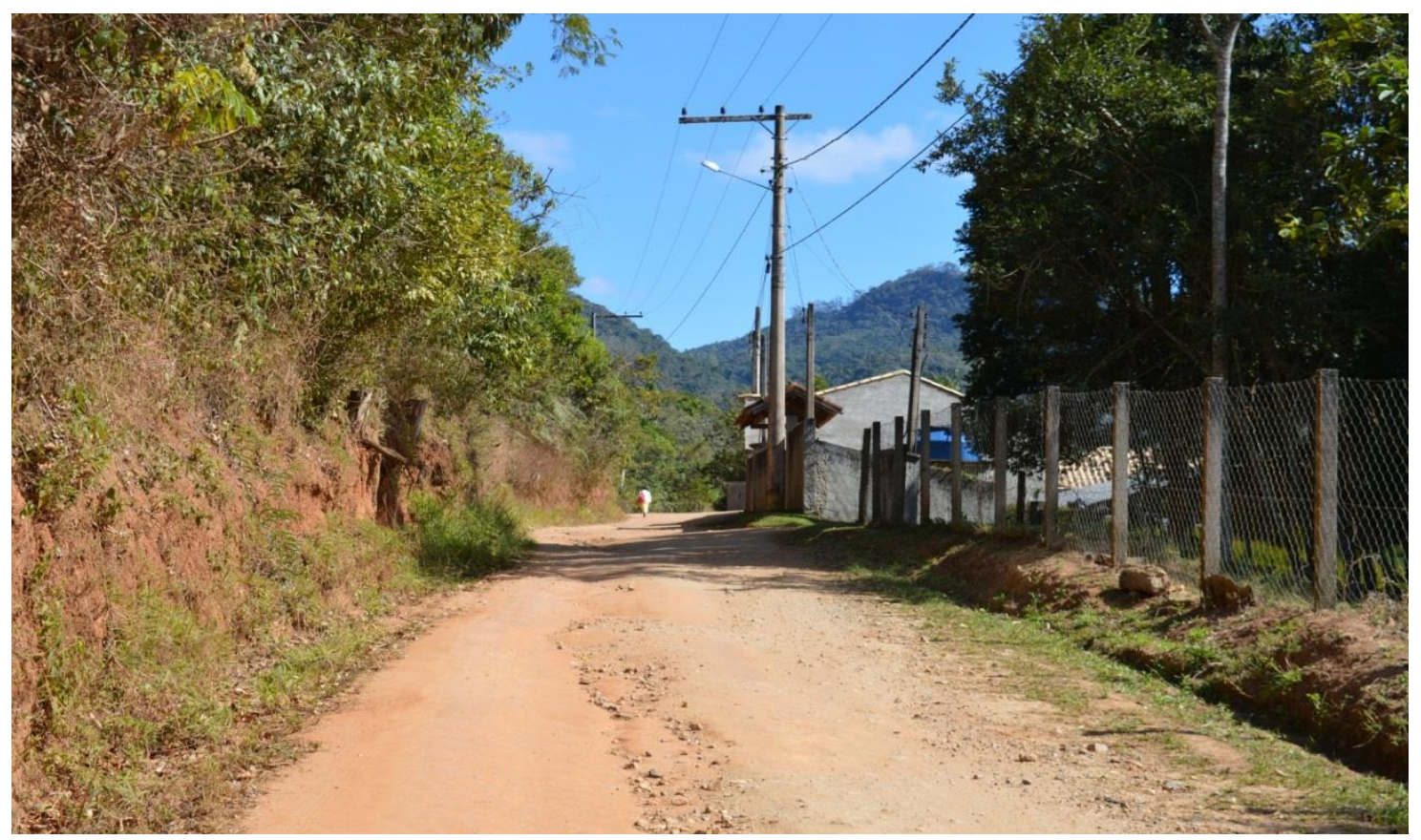

Outra debilidade encontrada em campo nos mesmos espaços foi perceptível por meio da ausência de sinais telefônicos nas localidades onde estão muitas propriedades floricultoras, algo que marca a dimensão 
temporal dessa rede geográfica. Sendo assim, não há uma instantaneidade nos fluxos de informações entre todos os agentes da cadeia, isso porque uma das pontas dela não se apresenta conectada. A coexistência do uso de insumos e técnicas modernas de produção, como o uso de estufas, além de outras, típicas da Revolução Verde, em espaços com atrasos nas densidades técnicas de circulação e comunicação são características que marcam o segmento de flores e plantas do estado do Rio de Janeiro.

Em São Paulo, muitas dessas debilidades foram superadas por meio das relações de cooperação entre os produtores e os demais elos da cadeia produtiva. No caso do Rio de Janeiro, entretanto, muitas das debilidades persistem. O fornecimento agrícola para a floricultura, por exemplo, baseada na oferta de sementes, adubos, defensivos e máquinas, em detrimento das novas técnicas que marcam a floricultura atual, como os cultivos protegidos (muitas propriedades já utilizam estufas), a produção de novos estratos, a fertirrigação e a micropropagação de mudas. Esses produtos quase sempre são buscados em empresas que se encontram fora do estado do Rio de Janeiro (vide figura 6), principalmente no mercado paulista, por meio de representantes dessas empresas ou quando os próprios floricultores se deslocam até ele (CARVALHO e CHIANCA, 2002). Esses autores ainda chamam atenção para o fato de que as empresas de insumos não adaptam seus produtos às condições edafoclimáticas e socioeconômicas do Rio de Janeiro, afetando a qualidade da produção.

Figura 6. Origem dos principais produtos consumidos nas lavouras floriculturas de Nova Friburgo - RJ Fonte: Adaptado por Reis, 2019, a partir de entrevistas realizadas em campo com a coordenadora de floricultura do RJ, floricultores, técnicos agrícolas, lojas agrícolas locais e representante do CADEG, em 2018

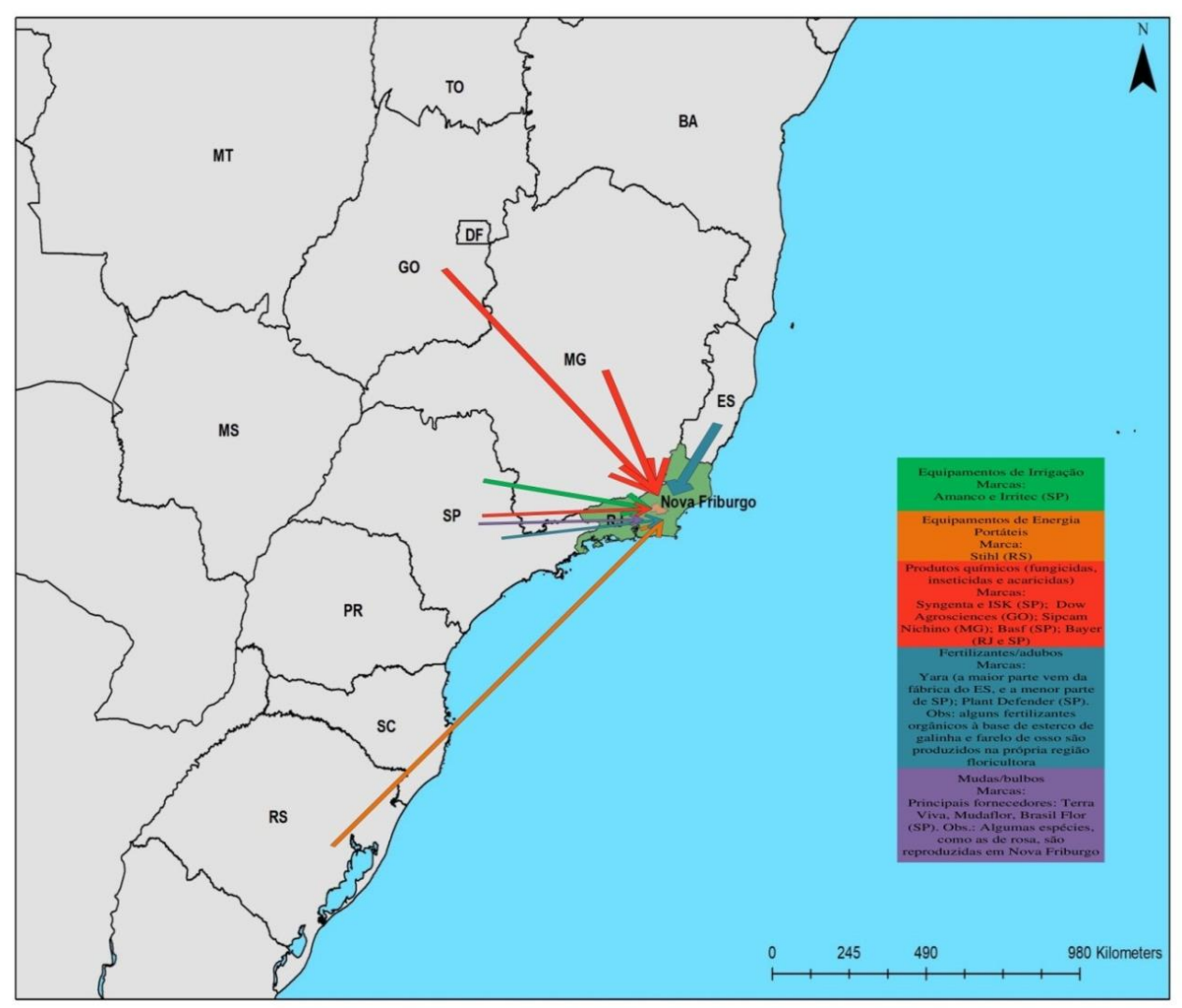


A interação entre os agentes espaciais assinalados e as empresas fornecedoras de insumos e equipamentos é de fundamental importância para o entendimento da dinâmica espacial da rede de flores e plantas ornamentais. Com base nos dados obtidos em campo, foi possível configurar o fluxograma da cadeia produtiva de flores e plantas ornamentais, tendo como referência o município serrano.

Fluxograma 1: Cadeia produtiva de flores de corte de Nova Friburgo Fonte: Adaptado por Reis, 2018, a partir de Lírio VS \& Silva CAB. In.: www.sebraerj.com.br. Acesso em: 10/06/2018;SEAPEC/EMATER-Rio, 2015; e entrevistas realizadas em campo com a coordenadora de floricultura do RJ, floricultores, lojas agrícolas locais, técnicos agrícolas e representante do CADEG, em 2018.

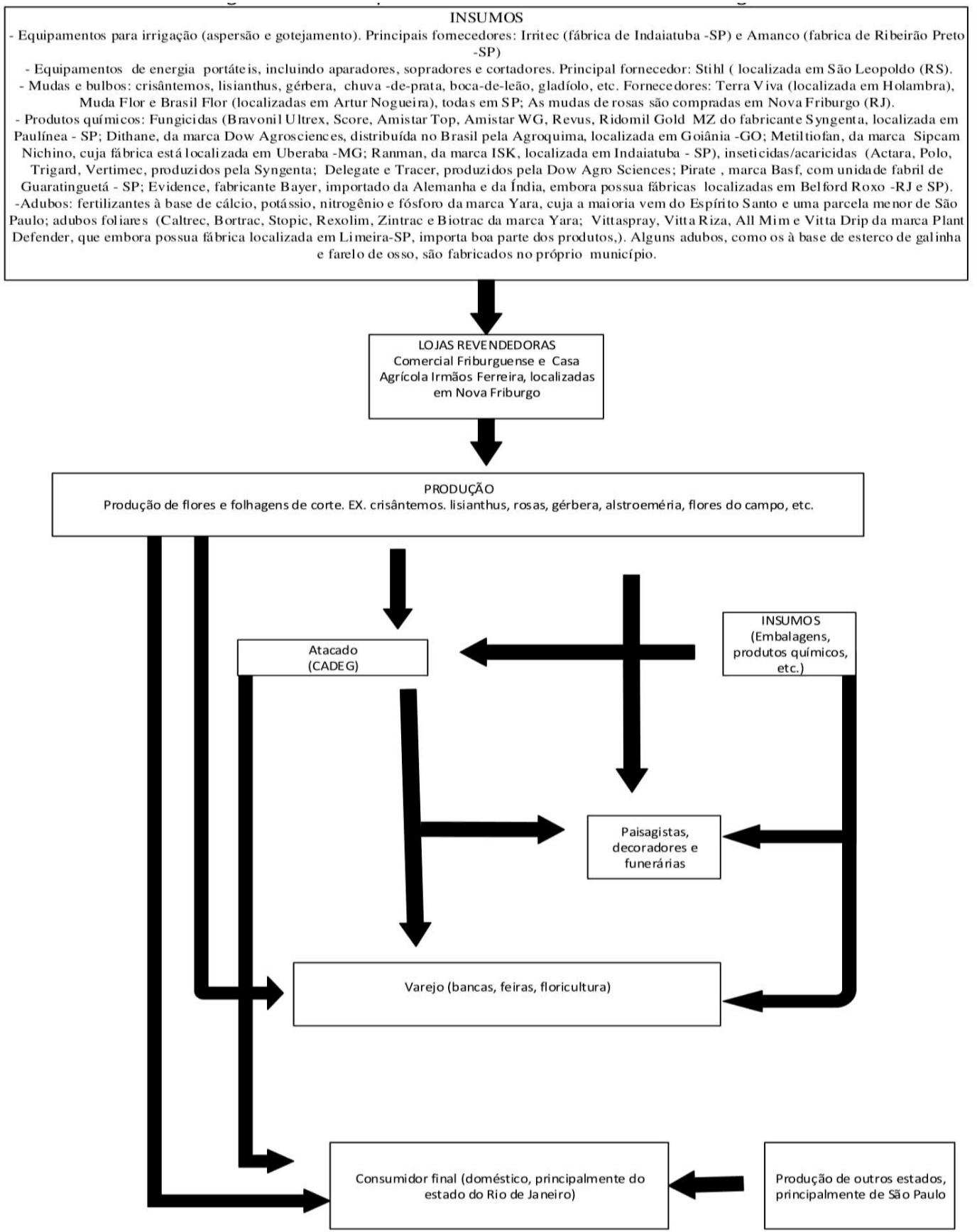


Embora muitos fornecedores possuam empresas instaladas no Brasil, o mapa 2 e o fluxograma 1 indicam que a origem delas (a maioria) encontra-se em outros países, o que permite entender que ainda que a produção desses equipamentos e insumos aconteça em território brasileiro, a circulação de capital ocorre em âmbito global, pois as sedes dessas empresas globais estão localizadas nos países de origem, ou seja, nos países mais ricos. Entende-se, portanto, que, nesse aspecto, a rede de produção e comercialização acontece na dimensão espacial nacional, mas que a circulação de capital ocorre na dimensão espacial global. Deve-se ressaltar que o acesso aos produtos ocorre dentro do próprio município de Nova Friburgo, sendo as empresas locais as grandes responsáveis pela articulação entre os representantes comerciais e os produtores.

Apesar de contar com instituições renomadas e órgãos estaduais de pesquisa, como o PESAGRO- RIO, o estado do Rio de Janeiro não apresenta grandes pesquisas no campo da floricultura. Aliás, durante o trabalho de pesquisa, foram encontrados poucos trabalhos minuciosos sobre este segmento no estado. Um deles, justamente o que foi realizado por Gustavo Kauark Chianca e René Louis de Carvalho, no ano de 2002, intitulado "A produção de flores e plantas ornamentais do estado do Rio de Janeiro: evolução recente, desafios e perspectivas". Do ano da publicação até o momento atual, foram verificadas algumas tentativas de desenvolver esse segmento no Estado, mas alguns dos desafios apontados continuam os mesmos, principalmente os ligados à pesquisa. Desse modo, não são notados contatos frequentes entre pesquisadores dessa área com os produtores, algo que não contribui para alavancar a produção em âmbito estadual.

À baixa contribuição das instituições de pesquisa no segmento de flores e plantas ornamentais, somase, também, o atendimento precário prestado pelo serviço público de extensão rural - EMATER -, que dispõe de um número reduzido de profissionais especialistas para atender à demanda da floricultura. Aliás, a falta de incentivo à formação de especialistas nas universidades acaba corroborando para o número reduzido desses profissionais no estado. Essa realidade, reconhecida pelos agentes do estado consultados, foi comprovada nas propriedades visitadas, cujos proprietários queixaram-se muito da assistência técnica prestada, que, na maioria das vezes, foi considerada ineficiente ou até mesmo inexistente.

Diferentemente do que ocorreu em São Paulo, no Rio de Janeiro o papel de incentivador e coordenador da floricultura não seria executado pelas cooperativas, mas por meio da atuação do Estado, sendo, portanto, este o principal agente espacial responsável pelo fortalecimento da rede de flores e plantas ornamentais em seu território. Pelo Estado, foi criado, mediante o decreto n. 934.335 , de 18 de novembro de 2003, o principal programa destinado à produção de flores e plantas ornamentais, intitulado Florescer.

\section{CONSIDERAÇÕES FINAIS}


A leitura do que foi exposto neste artigo permite entender que a rede de flores e plantas ornamentais global é dinamizada, principalmente pela Holanda, por meio de sua mais relevante cooperativa, a FloraHolland. Ainda que sejam observados outros agentes na rede global, a supremacia holandesa é marcante. Já a rede de flores e plantas ornamentais de São Paulo apresenta uma configuração nacional - apesar de manter relações com outros agentes globais. Entre os principais agentes de sua rede, destacam-se as cooperativas sediadas no município de Holambra. Essas cooperativas paulistas, inclusive, vendem seus produtos no território fluminense, que, por sua vez, apresenta uma rede de flores mais regional, tendo a maior parte de sua produção comercializada no mercado atacadista localizado no município do Rio de Janeiro. No estado do Rio de Janeiro, destacam-se as políticas setoriais - como o Programa Florescer -, que tentam modernizar a sua rede de flores e plantas ornamentais. Independentemente de seus resultados, indicam que a articulação dessa rede vem sendo mediada pelo governo estadual.

Há de se ressaltar que, no estado do Rio de Janeiro, a rede de flores já existia, antes mesmo do interesse estatal, e continua a existir, ainda que as ações do governo sejam consideradas incipientes para o segmento e que sejam observadas características nos espaços de circulação das mercadorias que tendem a limitar os fluxos entre as áreas de produção e o principal mercado atacadista, o CADEG, localizado no município do Rio de Janeiro.

Entre os pontos que tendem a limitar os fluxos entres as áreas de produção e de circulação, deve-se registrar o mal estado de conservação de muitas estradas que dão acesso a essas áreas, o que dificulta a saída da produção das propriedades floricultoras, prejudicando, de tal modo, a fluidez das mercadorias. Essa situação torna-se relevante porque os fixos são de fundamental importância para facilitar a circulação de mercadorias, e quando eles encontram-se precários, há forte interferência nas relações que são estabelecidas entre os pontos da rede. Do mesmo jeito, a ausência de sinais telefônicos nas áreas de produção é algo que tende a restringir o contato entre produtores, fornecedores e consumidores e também corrobora para tornar a rede de flores do Rio de Janeiro menos integrada, quando comparada com as outras redes evidenciadas ao longo da investigação.

A maior parte dos produtos consumidos nas lavouras vêm de fora do estado, o que, inevitavelmente, nesse aspecto, faz esta dimensão espacial extrapolar à dimensão regional: são produtos oriundos principalmente da região Centro-Sul. No que diz respeito à dimensão espacial de consumo do que é produzido em Nova Friburgo, pode-se afirmar que quase a totalidade do que se produz fica em território fluminense, sendo o Centro de Abastecimento do Estado da Guanabara (CADEG) o principal mercado distribuidor.

Interessante notar que as dimensões espaciais tratadas ao longo desse trabalho mostram a interligação cada vez maior entre os espaços rural e o urbano. E isso fica evidenciado pelos produtos que são consumidos 
nas floriculturas, oriundas de cidades de outras partes do Brasil, assim como as flores produzidas no campo e que são consumidas nas cidades, como as flores vendidas na capital fluminense.

A análise da dimensão espacial aqui tratada não deixa de evidenciar os problemas encontrados nos diferentes pontos da rede e que necessitam, obviamente, de uma solução conjunta entre todos os elementos espaciais destacados ao longo da pesquisa. A busca pela solução desses problemas torna-se fundamental para dar fluidez a essa rede. O primeiro ponto a ser destacado é a visibilidade que o governo estadual precisa dar às suas ações em relação ao segmento. Como um programa que foi projetado para ser o principal do setor é tão desconhecido por boa parte dos produtores?

A política de crédito não é a principal reivindicação do segmento. Ela é importante, mas não é fundamental, como as obras de infraestrutura que precisam ser executadas nos espaços de circulação, sejam eles em âmbito estadual ou municipal. Não há como garantir a fluidez da produção se os fixos que dão acesso às propriedades encontram-se em condições precárias. Então, torna-se indispensável a atuação estatal, nas mais diferentes esferas administrativas, a fim de se contornar essa situação.

São necessários, também, investimentos em pesquisa e preparo técnico, pois foram falhas observadas ao longo do trabalho e que expõem a dependência da rede de flores fluminense em relação à rede de flores paulista.

Há de ressaltar que o imbróglio envolvendo os produtores e o principal mercado atacadista, o CADEG, precisa ser resolvido, pois trata-se de um ponto já consolidado na cidade do Rio de Janeiro como referência na venda de flores. Talvez essa situação possa ser contornada a partir da criação de uma cooperativa, algo citado como fundamental pelos produtores para a tomada de decisões, não só para a compra de insumos e mudas diretamente da fábrica, mas, também, para que possa servir como interlocutora na resolução de problemas como o que se encontra em curso, assim como no apontamento de outras possibilidades de expansão da floricultura no estado.

Essas ações tornam-se relevantes porque foram percebidas, ao longo da pesquisa, que elas envolvem um número expressivo de famílias que vivem desse segmento e que, portanto, geram renda e recursos para as famílias e para o Estado.

Sabendo-se que o estado do Rio de Janeiro é muito dependente das atividades ligadas à exploração do petróleo - e também suscetível às suas variações de preço -, investir em outros setores, como o segmento de flores de corte e plantas ornamentais, é imprescindível. Os valores expressos e a participação do faturamento do Rio de Janeiro em âmbito nacional mostram o quanto esse segmento pode ser importante para a diversificação da economia fluminense 


\section{REFERÊNCIAS}

AGRO Link Portal de Conteúdo Agropecuário. Agrolinkfito. Disponível em: <https://www.agrolink.com.br/agrolinkfito/busca-diretaproduto>. Acesso em: 17 mar. 2019.

AGROQUIMA Produtos Agropecuários Ltda. Dithane NT. Disponível em: <http://www.agroquima.com.br/produto/dithane-nt/158>. Acesso em: 17 mar. 2019.

AMANCO: Mexichem Building \& Infrastructure. Irrigação. Disponível em: <http://amanco.com.br/produtos\#categoria-irrigacao>. Acesso em: 17 mar. 2019.

BARBOSA, Pedro Biazzo de Castro. “A constituição de uma periferia em face da modernização: a produção de açúcar e álcool no Brasil e as transformações na Região Norte Fluminense". In: MARAFON, G. J. \& RIBEIRO, M. A. (orgs). Revisitando o território fluminense. Rio de Janeiro: NEGEF, 2003. p. 111-148.

BAYER S/A. Página inicial. Disponível em: <https://www.bayer.com.br/a-bayer/historia/>. Acesso em: 23 mar. 2019.

BLOG Ibid system solution. Página inicial. Disponível em: <https://ibid. com.br/blog/leilao-reverso/>. Acesso em: 05 mai. 2018.

BRANDÃO, Antônio Salazar P. “O polo de fruticultura irrigada no norte e noroeste fluminense”. In: Revista de Política Agrícola. Ano XIII, n. 2. Abr/mai/jun, 2004. p. 78-86.

BRASIL Flor Mudas de Crisântemos. Página inicial. Disponível em: <https://www.brasilflor.com.br/empresa.php/>. Acesso em: 23 mar. 2019.

CARNEIRO. Maria José. "Política pública e agricultura familiar: uma leitura do Pronaf”. In: Estudos sociedade e agricultura, n.ㅇ 8. Rio de Janeiro: CPDA/UFRRJ, 1997. Pp. 70-82.

CARVALHO, Louis de Carvalho e CHIANCA, Gustavo Kauark. "A produção de flores e plantas ornamentais do Estado do Rio de janeiro: evolução recente, desafios e perspectivas". p. 97-112. In: Pesquisa Agropecuária \& Desenvolvimento Sustentável, v. 1, n.o 1, p 1112 dez (2002). Niterói: Pesagro-Rio,2002.

CASA Agrícola Irmãos Ferreira. Página inicial. Disponível em: <http://www.irmaosferreira.com.br>. Acesso em: 04 jan. 2019.

CEASA. Ceasa Campinas. Página inicial. Disponível em: <http:// www.ceasa campinas.com.br/novo/Inst_Flores.asp >. Acesso em: 12 maio 2018.

COOPERFLORA. Cooperflora: especialista em flor. Página inicial. Disponível em:

<http://www.cooperflora.com.br/cooperflora/comercializacao-e-distribuicao/>. Acesso em: 05 maio 2018.

COORDENAÇÃO DO PROGRAMA FLORESCER. Cadeia produtiva da floricultura no estado do Rio de Janeiro. Rio de Janeiro: SEAPEC/EMATER/RIO, 2015.

CORRÊA, Roberto Lobato. "Espaço: um conceito-chave da Geografia”. In.: Castro, Iná Elias de. et al (orgs). 4o ed. Rio de Janeiro: Bertrand Brasil, 2002, p.15-45.

CORRÊA, Roberto Lobato. “Redes Geográficas: reflexões sobre um tema persistente”. In: Revista Cidades. Presidente Prudente: Unesp, v. 9, no 16, 2011. Pp. 199-218.

CORTEVA Agriscience. Página inicial. Disponível em: <https://www. corteva.com.br/quem-somos/nossa-fusao.html>. Acesso em: 23 mar. 2019.

CORTEVA Agriscience. "Multinacional celebra um ano de lançamento da marca e tem Brasil como peça-chave para crescer". São Paulo, 22 mar. 2019. Disponível em: <http:// patrocinados.estadao.com.br/corteva/2019/03/22/multinacional-celebra-um-ano-delancamento-da-marca-e-tem-brasil-como-peca-chave-para-crescer/>. Acesso em: 23 mar. 2019.

DIERBERGER. Dierberger tropicais. Página inicial. Disponível em: <http://

dierbergertropicais.com.br/web/index.php?option=com_content\&view=article\&id=37\&ltemid=4>. Acesso em: 5 maio 2018.

ELIAS, Denise. "Globalização e agricultura no Brasil”. In: GEO UERJ - Revista do Departamento de Geografia, no 12. Rio de Janeiro: UERJ, 2002, p. 23-32.

EMPRESA Brasileira de Pesquisa Agropecuária. Página inicial. Disponível em: <https://www.embrapa.br/busca-de-publicacoes//publicacao/ 886343/ fertirrigacao>. Acesso em: 2 jun. 2018.

ENCONTRA COTIA. Roselândia em Cotia. Página inicial. Disponível em: <http:// www.encontracotia.com.br/cotia/roselandia-emcotia.shtml>. Acesso em: 5 maio 2018.

ESCALONA. Belkys Rojas de. Investigación Cualitativa. Fundamentos y práxis. 3o ed. Caracas: FEDUPEL, 2014,229 p.

FIRJAN. “O Sistema Firjan e a Governança Estadual dos Arranjos Produtivos Locais”. In: Simpósio de Gestão da Inovação Tecnológica. Curitiba-PR: Gerência de Desenvolvimento Tecnológico do Sistema FIRJAN, 2004. 
FUSCO. Fabrício Marini. Nem o céu, nem a terra: reflexões sobre a relação rural/urbano no estado do Rio de Janeiro. In: MARAFON, G. J. \& RIBEIRO, M. A. (orgs). Revisitando o território fluminense II. Rio de Janeiro: Gramma, 2008. Pp. 17-39.

GRANFLORA. Gran Flora Veiling. Página inicial. Disponível em:<http:// www.granflora.com.br/quem-somos/>. Acesso em: 12 de maio de 2018.

GUANZIROLI, Carlos et al. Agricultura familiar e reforma agrária no século XXI. Rio de Janeiro: Garamond, , 2001. Pp. 15-43.

IANNI, Octavio. O mundo agrário. In: A era do globalismo. Rio de Janeiro: Civilização Brasileira, 1996, pp.43-63.

INSTITUTO Brasileiro de Floricultura. Ibraflor, c2018. Disponível em:<http://www. ibraflor.com/site/quem-somos/>. Acesso em: $13 / 05 / 2018$.

INSTITUTO Brasileiro de Geografia e Estatística (IBGE). Caracterização do setor produtivo de flores e plantas ornamentais no Brasil, 1995-1996. Rio de Janeiro: IBGE, 2004.

INSTITUTO Brasileiro de Geografia e Estatística: Censo Agropecuário 1995-1996. Rio de Janeiro: IBGE, n.1,1998. 366 p.

IRRITEC. S. P. A. Irritec, c2019. Página inicial. Disponível em:<http://new.irritec.com/ pt-br/empresa/historia>. Acesso em: 17 de mar. de 2019.

JORNAL O DIA. "Flores se expandem no interior: estado já é o segundo maior produtor. Municípios de várias regiões aderem ao cultivo". Rio de Janeiro, 29 jun. 2014. Disponível em:<http://odia.ig.com.br/odiaestado/2014-06-29/flores-se-expandem-nointerior.html>. Acesso em: 16 ago. 2016.

LIMA, Marcos R. Ornelas et al. Regiões de Governo do Estado do Rio de Janeiro: uma contribuição geográfica. Rio de Janeiro: Gramma, 2005, 139 p.

LÍRIO VS \& SILVA CAB. Diagnóstico da cadeia produtiva de flores e plantas ornamentais no Estado do Rio de Janeiro. Rio de Janeiro, UFV/FUNARBE, 2003, $157 \mathrm{p}$.

MARQUES. M. I. M. “O conceito de espaço rural em questão”. In: Revista Terra Livre. São Paulo: Terra Livre, v. 18, n.o 19, 2002, p. 95112.

MUDAFLOR. Mudaflor, c2018. Página inicial. Disponível em: <http://www.mudaflor. com.br/empresa.php>. Acesso em: 23 mar. 2019.

NATAL, Caroline Bezerra. O turismo na Região Serrana Fluminense: um estudo de caso - São Pedro da Serra. In: MARAFON, G. J. \& RIBEIRO, M. A. (orgs). Revisitando o território fluminense. Rio de Janeiro: NEGEF, 2003. Pp. 169-185.

NEVES, M. F.; PINTO, M. J. A. (Orgs.) Mapeamento e quantificação da cadeia de flores e plantas ornamentais do Brasil. São Paulo: OCESP, 2015. 132p.

OLIVEIRA, Ariovaldo Umbelino de. "Agricultura brasileira: transformações recentes". In: ROSS, Jurandyr L. S. (org.). Geografia do Brasil. São Paulo: EDUSP, 1996, p. 467-534.

PIZZOLATTI, Roland Luiz. “Globalização e a pequena produção “integrada”. In: X Congresso Mundial de Sociologia Rural e XXXVIII Congresso Brasileiro de Economia Sociologia Rural. Rio de Janeiro. Jul/ago, 2000, p. 1-9.

PLANT Defender Tecnologia Agrícola Importacao e Exportacao Ltda. Empresas CNPJ, c2019. Página inicial. Disponível em: <https://www.empresascnpj.com/s/empresa/plant-defender-tecnologia-agricola-importacao-e-exportacao-Itda/08812328000114>. Acesso: 23 mar. 2019.

PLANT Defender Tecnologia Agrícola Importacao e Exportacao Ltda. Empresas CNPJ. Página inicial. Disponível em: http://plantdefender.com.br/produtos/vittaspray>. Acesso em: 17 mar. 2019.

PORTAL AgroRevenda: informações do varejo agropecuário. Agrorevenda, c2018. Página inicial. Disponível em: <https://www.agrorevenda.com.br/ourofino-agrociencia-anuncia-parceria-estrategica-com-japonesas-mitsui-e-isk/>. Acesso em: 23 mar. 2019.

REIS, Jorge Luiz Costa da Silva. Os impactos do programa Frutificar no espaço rural fluminense. Monografia de especialização em Geografia. UERJ, 2010.

REIS, Jorge Luiz Costa da Silva. "A dimensão espacial da rede de flores e plantas ornamentais do estado do Rio de Janeiro: uma análise a partir do município de Nova Friburgo, entre os anos de 2002 e 2018 ". Dissertação (mestrado em Geografia) - Instituto de Geografia, Universidade do Estado do Rio de Janeiro. Rio de Janeiro. 2019. 121p.

Revista Exame: Grupo Abril. "BASF fecha aquisição de negócios e ativos da Bayer: Desinvestimentos são necessários para que o fabricante da aspirina possa adquirir a Monsanto". São Paulo, 1ำ ago. 2019. Disponível em: <: https://www.exame.abril.com.br/negocios/basf-fecha-aquisicao-de-negocios-e-ativos-da-bayer/. Acesso em: 23 mar. 2019.

REYES, M. FAO. La función de los mercados mayoristas em los centros urbanos de Colombia. Organización de las naciones unidas para la agricultura y la alimentación - FAO. Medellín, Colombia: 2012. 
RUA, João. "Urbanização em áreas rurais no Estado do Rio de Janeiro". In: MARAFON, Gláucio José e RIBEIRO, Marta Foeppel (orgs). Estudos de Geografia Fluminense. Rio de Janeiro: Infobook, 2002. P. 43-70.

SANTOS. Milton. Espaço e método. 3a ed. São Paulo: Nobel, 1992. 88p.

SANTOS. Milton e SILVEIRA, Maria Laura. "Uma reorganização produtiva do território". In: O Brasil: território e sociedade no século XXI. 4ạ ed. Rio de Janeiro: Record, 2002. P. 105-141.

SEAPEC. "Floricultura movimentou R\$ 634 milhões no estado em 2014: setor também ampliou número de produtores e de áreas cultivadas". Rio de Janeiro, 31 mar. 2015. Disponível em: <http://www.rj.gov.br/web/seapec/exibeconteudo?article-id=2384894>. Acesso em: 16 ago. 2016.

SEAPEC. "Floricultura terá um R\$ 1 milhão no próximo ano Itaboraí é o segundo maior produtor de plantas ornamentais e flores do estado e teve um crescimento de área plantada de $47 \%$ nos últimos 10 anos". Rio de Janeiro, 25 nov. 2013. Disponível em: <http://www.rj.gov.br/web/seapec/exibeconteudo?article-id=1859710>. Acesso em: 16 ago. 2016.

SEAPEC. "Floricultura fluminense ganha espaço nacional para pleitear incentivos: ASBRAER é representada na Câmara Setorial de Floricultura e Plantas Ornamentais por gerente estadual da Emater-Rio". Rio de Janeiro, 28 jul. 2015. Disponível em:

<http://www.rj.gov.br/web/seapec/exibeconteudo?article-id=2512331>. Acesso em: 16 ago. 2016.

SEBRAE. Página inicial. Disponível em: <http://www.sebraerj.com. br>. Acesso em: 10 jun. 2018.

SECRETARIA de Agricultura, Pecuária, Pesca e Abastecimento. SEAPEC, c2018. Página inicial. Disponível em: <http://www.fazenda.rj.gov.br/sefaz/faces/oracle/ webcenter/portalapp/pages/navigationrenderer.jspx?afrLoop=2140951551191089 \&datasource=UCMServer\%23dDocName\%3A98984\&_adf.ctrl-state=893yfm6y3_9>. Acesso em: 02 jun. 2018.

SECRETARIA de Agricultura, Pecuária, Pesca e Abastecimento. SEAPEC. Página inicial. Disponível em: <encurtador.com.br/dtxTY>. Acesso em: 02 jun. 2018.

SECRETARIA de Agricultura, Pecuária, Pesca e Abastecimento. SEAPEC. Página inicial. Disponível em: <encurtador.com.br/BHIJZ. Acesso em: 02 jun. 2018.

SECRETARIA de Agricultura, Pecuária, Pesca e Abastecimento. SEAPEC. Página inicial. Disponível em: <encurtador.com.br/cfzP7. Acesso em: 02 jun. de 2018.

SECRETARIA ESTADUAL DE AGRICULTURA E PECUÁRIA. Disponível em: <http:// www.rj.gov.br/web/seapec/principal>. Acesso em: 16 ago. 2016.

SILVA, Augusto César Pinheiro da. "As estratégias de modernização do rural fluminense: técnica, planejamento e gestão no campo do Rio de Janeiro". In: Campo Território, Revista de Geografia Agrária, n. 2, v. 1, ago. 2006. P 92-12.

SILVA, Cláudia Maria Arantes. "Modernização da agricultura brasileira e relações de trabalho no campo: a diversidade de estratégias que permeiam a inserção da pequena produção familiar de Nova Friburgo-RJ na lógica capitalista de produção". In: MARAFON, G. J. \& RIBEIRO, M. A. (orgs). Revisitando o território fluminense II. Rio de Janeiro: Gramma, 2008. Pp. 231-261.

SILVA, José Graziano da. "O novo rural brasileiro". In: O novo rural brasileiro. Campinas, SP: UNICAMP/IE, 1999. Pp 1-32.

SIPCAM Nichino Brasil S/A. Sipcam Nichino, c2014. Página inicial. Disponível em:< http://www.sipcamnichino.com.br/empresa.php/>. Acesso em: 17 mar. 2019.

SOFLOR. c2018. Página inicial. Disponível em: <encurtador.com.br/gkvKW>. Acesso em: 12 maio 2018.

SOUZA, José Luiz A. M. "Reestruturação do espaço agrário no município de Quissamã e inserção de novas atividades agrícolas". IN: MARAFON, G. J. \& RIBEIRO. M. A. (orgs). Rio de Janeiro: NEGEF, 2003. Pp. 207-236.

SOUZA, José Luiz A. M. "Transformações no espaço rural através de políticas agrícolas: o programa Frutificar e a cultura do coco em Quissamã-RJ”. In: MARAFON, G. J. \& RIBEIRO, M. A. (orgs). Revisitando o território fluminense II. Rio de Janeiro: Gramma, 2008. Pp. 305-325.

STHIL Ferramentas Motorizadas Ltda. Página inicial. Disponível em: <https://www.stihl.com.br>. Acesso em: 05 jan. 2019.

SYNGENTA Brasil. Portal Syngenta. Página inicial. Disponível em: <https:// www.portalsyngenta.com.br>. Acesso em: 05 jan. 2019. TERRA VIVA: plantamos uma vida melhor. Página inicial. Disponível em: <https://www.terraviva.agr.br/>. Acesso em: 23 mar. 2019.

UMBELINO, Luiz Felipe. “A difusão da Agricultura Orgânica na Região Serrana do Estado do Rio de Janeiro”. In: MARAFON, G. J \& RIMEIRO. M. A (orgs). Revisitando o território fluminense. Rio de Janeiro: NEGEF, 2003. Pp. 149-168.

VEILING Holambra. Veiling Holambra flores e plantas ornamentais. Página inicial. Disponível em: <http://www.veiling.com.br/>. Acesso em: 05 maio 2018.

YARA Brasil Fertilizantes. Página inicial. Disponível em:< encurtador.com.br/dqGJ6>. Acesso em: 05 jan. 2019. 